\title{
Innovations for sustainable lifestyles: an agent-based model approach
}

\author{
P. Allen ${ }^{1} \cdot$ M. Robinson ${ }^{1} \cdot$ E. Butans ${ }^{1} \cdot$ L. Varga ${ }^{1}$
}

Received: 29 June 2017 / Accepted: 13 June 2018/Published online: 28 June 2018

(C) The Author(s) 2018

\begin{abstract}
An important aspect of any scientific approach to sustainability must be methods by which the impacts of possible innovations can be assessed. Clearly, we need to make massive changes in our lifestyles if we are to get anywhere near 'sustainability'. In this paper, an 'agent-based model' is developed which for this initial presentation explores probable impacts on household consumption and emissions of possible innovations. The model randomly picks a large number (here 10,000 , but it can be much larger) of households from four different countries and calculates the effects resulting from the adoption of specific innovations. The 'lifestyle' of the households within the area studied is divided into four different 'domains'. These are living, food, mobility and energy. Innovations are launched in the four different domains and the model shows the overall effects on the total input requirements (materials, energy, etc.), the household and food wastes and the $\mathrm{CO}_{2}$ emissions, showing how far the system moves towards sustainability. By using the sustainability criteria of $8000 \mathrm{~kg}$ 'input material' per year per individual developed by the Wuppertal Institute (Lettenmeier et al. in Resources 3:488-515, 2014, https://doi.org/10.3390/resources3030488, http://www.mdpi.com/journal/resources, ISSN 2079-9276), we can calculate how far the nation or region is from sustainability after adopting possible innovations. This is a measure of the total inputs required per individual per year. It allows us to show that for different countries, with widely different climates (e.g. Finland and Spain), different household innovations would have a greater or lesser impact on attaining 'sustainable lifestyles'. The model does not pretend to develop a full simulation of each system, including the ecosystem, type of economy, etc., but does look at the effect an innovation in one household domain will have on all four domains, thereby providing information that can improve current decisions. It also demonstrates that, although 'households' can do much to improve the situation by reducing their demand for energy and materials, some actions at a national/regional level will be required to achieve sustainability. For example, sustainability will require an end to the use of fossil fuels for transportation and a switch to 'clean' electrical power generation from renewables and nuclear sources. Without this change, these countries will find it impossible to reach a sustainable lifestyle.
\end{abstract}

Keywords Sustainable consumption $\cdot$ Emissions $\cdot$ Household innovations $\cdot$ Comparing countries

\section{Introduction}

With the development of computers, modelling of real systems and situations was able to move on from simply assuming the system went from one equilibrium to another. It became possible to represent the dynamical and even evolutionary changes that might occur over time. Initially,

Handled by Karel F. Mulder, The Hague University of Applied Science, The Netherlands.

P. Allen

p.m.allen@cranfield.ac.uk

1 School of Management, Cranfield University, Bedford, UK the first step was system dynamics (Forrester 1961; Meadows et al. 2004; Sterman 2000) which described the changes occurring in a system as a result of the interactions between its constituent elements, which in social systems could be different types of agent. But in system dynamics, elements and agents only interact in 'average' ways, according to their type. The study of systems whose elements and agents exhibited nonlinear interactions led to the development of complex systems models capable of selforganization and of creating new collective, levels of interaction (Prigogine 1997). Such systems were sensitive to microscopic fluctuations, leading to different possible dynamical attractors, regimes of system operation and futures. More importantly, perhaps they were sensitive to the diversity of characteristics and capacities, which could 
provide the basis for adaptation, evolutionary changes and learning (Holland 1996; Allen 2013).

Agent-based modelling (ABMs) can use the actual statistics of a situation (the distributions and not just the averages) to set up and run dynamic models (Bonabeau 2002; Gilbert 2007; Miller and Page 2007). This can include both competitive and synergistic non-linear interactions between elements and agents and applies to the whole of management, decision making, organization and innovations (The sage handbook of complexity and management 2011). But, modelling and exploring 'possible futures' for a 'real' situation, such as the material and energy flows of households, requires at the very least the inclusion of variables and interactions concerning the ecosystem, environment, economy, local culture, climate and technological changes. However, in this paper, our intention is not to try to build a full simulation of each system, but to examine the impact arising from the adoption of a given innovation by households, calculating both the direct effects on the immediate domain and also the secondary ones on the other domains of the household. We are interested in being able to explore the resulting changes in the environmental footprint of households and in using this information to suggest to policy makers which innovations would be most effective.

Households are one of the largest contributors globally to carbon emissions. But the 2008 Climate Change Act requires (a) 34\% cut in 1990 greenhouse gas emissions by 2020 and (b) at least an $80 \%$ cut in emissions by 2050 . It will be impossible to meet the 2050 objective without moving away from fossil fuels, both for transport and for energy generation (Palmer and Cooper 2012). Urban areas are responsible for in excess of $70 \%$ of these (Dodman 2009). In Ivanova et al. (2016), the environmental impact of household consumption is studied using a multiregional input-output database. They show the carbon, land, materials and water footprints per individual for different countries. This shows the collective impact of households on the environment, revealing the overall effects of different situations and lifestyles. In our study here, however, we are concerned with how far potential innovations might reduce household demands on the environment, whilst retaining the natural diversity of household behaviours within each study. Reducing the emissions from households in our towns and cities is a significant international challenge. Reductions of $80 \%$ on 1990 levels by 2050 have been promised by the signatories of the Paris Agreement on Climate Change (Paris agreement on Climate Change 2016) and clearly households will be key in achieving these changes. The different factors that contribute to resource use and emissions have been divided into different domains-namely, 'living, food, mobility and energy'. Clearly, these domains interact as we try to keep warm, to cook our food, dispose of our household and food waste, and travel to and from work and to the shops. Our current lifestyles are completely unsustainable over coming decades as we use far too much energy and material flowsfor example on average around $31,000 \mathrm{~kg}$ of 'inputs' per person-where a sustainable level would be around $8000 \mathrm{~kg}$ (Robinson 1990). The model we develop here is neither simply about forecasting nor backcasting (Rijnhout and Lorek 2011). We build an ABM model of the flows into and out of households of a region and use it to calculate the impacts of different possible innovations on these. We do, however, look at these possibilities using the idea that a reduction of these towards $8000 \mathrm{~kg}$ of material footprint would be closer to sustainable. This allows us to examine their relative impacts in the different countries studied, and hence to provide policy advice concerning which innovations would be most effective. The output of our model is in terms of the total material input requirements per individual and how far they are above the suggested $8000 \mathrm{~kg}$ (Lettenmeier et al. 2009; Lettenmeier et al. 2014; Ritthoff et al. 2002). We can see how great the changes required will be if we are ever to arrive at a sustainable lifestyle. The model that we have developed here aims to illuminate the possible household innovations that could be adopted by households, leading to an exploration of possible low carbon scenarios for the chosen examples (Gomi et al. 2007). The model provides an approach that advances the science of sustainability by helping the choice of innovations to be promoted as well as improving the design of future housing and urban planning (Advancing sustainability science: report on the International Conference on Sustainability Science (ICSS) 2009). We focused on households, however, and did not consider specifically the sustainability or input footprints of organizations and businesses themselves, or the actual patterns of travel to and from work. Both of these would certainly play an important part in any sustainable lifestyle (Garcia-Mera et al. 2017). However, in our development of this initial non-spatial ABM, we decided that this could only be included in an approximate fashion. We included innovations involving reductions in travel, especially car travel, but not specifically attached to particular changes in commuting distances.

Clearly, interactions between agents could affect the rate at which innovations might spread, due to imitation and economies of scale, but here, as a first step we simply wish to look at the effect of the adoption of possible innovations, to provide innovation policy advice.

Another issue that we have not considered explicitly is that of 'servicizing', where households might change from acquiring products for themselves and adopt companies that offer services (Van der Veen et al. 2017). However, quoting Tukker, "For consumers, having control over 
things, artefacts, and life itself is one of the most valued attributes. PSS (Product Service Systems) are often less accessible, or have less intangible value, than the competing product, in part because PSS usually do not allow consumers as much behavioural freedom or even leave them with the impression that the PSS provider could prescribe how they should behave" (Tukker 2015). Clearly, then it seems that at present this is really one kind of innovation that might have a large impact on household footprints, but it is not yet clear how much. In the model developed here, we try to keep to a 'simple' study of households and their footprints.

\section{The EU-innovate simulation model}

The simulation model is an agent-based model developed using MATLAB software ("Matlab," 2016). This software platform was chosen ahead of other potential alternatives (AnyLogic, Repast Simphony, Python, Netlogo) because of its ability to run in multi-processor mode, customization capacity, performance capacity and its ability to execute the model by a third party without the need for a MATLAB licence.

\section{Problem definition}

The model addresses the following research problems: Are there scenarios of domestic consumption behaviours which can move us closer to sustainable lifestyles? Can the transition from contemporary lifestyles to sustainable lifestyles be achieved via user innovations in domestic consumption behaviours? How can this transition be achieved?

The EU-Innovate model addresses these problems by simulating artificial societies, representative of any scale of community, and assessing the following:

the sustainability performance of domestic consumers (current or future);

the sustainability performance of systemic innovation targeted at domestic consumers in a society (current or future);

the impact upon sustainability performance from the adoption of user innovations in four household domains: food, energy, living and mobility;

the effect of policies or societal changes (e.g. marketing, increased trust) upon the adoption of user innovation in the short and long term;

the impact of policies or societal changes which are targeted at different sizes of household: small, medium or large;

transition pathways to sustainable domestic lifestyles; identification of user innovation types and adoption rates that have the greatest potential to achieve sustainable lifestyles; and

verification of the assumptions of policy intervention into sustainable lifestyles.

\section{Model design}

The model is 'agent based' and corresponds to a population of households that stochastically adopt innovations. Each agent corresponds to a household. The model is designed to explore the overall consumption of the system, using sustainable performance metrics of carbon emissions and kilograms of consumption per individual. In other words, it calculates the changing 'sustainability' of the system of households in terms of their reduced 'input footprints' and outputs of emissions and wastes. Scenario data provide the baseline information for the artificial simulated society. The model uses national, annual consumption data for the four domains which is reasonably accessible via government statistics websites. However, the model is entirely flexible and can create scenarios based on any scale, provided that good data can be determined at the preferred scale. Innovation Data provide the information on what areas of consumption are improved and the magnitude of change in consumption.

The key to the model design is to recognize the integrated nature of households. The schematic in Fig. 1 shows overlapping domains: green for food, red for energy, blue for living and yellow for mobility. Coloured lines show the relationships, for example, food waste is accumulated into household waste, as is waste from household occupancy. Household occupancy itself determines the food consumed and the energy used, and the energy used depends on the particular types of energy installed in particular households. Mobility emissions depend on fuel, choices of transport and miles travelled. Mobility fuel consumption resides in both energy and mobility domains and so on (Figs. 2, 3, 4, 5).

Model initial conditions are driven by the scenario data. The agents/households in the model are sufficiently numerous to be considered as representative of the system as a whole. For example, in the model used in the output shown below, we have picked 10,000 households from the millions available in the UK, Germany, Spain and Finland. The model can easily be set to take up to a million households - it just takes longer to run.

The households are representative of the statistical distributions of the data. This is achieved by probabilistic means. For example, the proportions of households with different floor areas may vary (Table 1 ) (i.e. the values $A$, $B, C, D$ and $E$ need only to add up to 1$)$. Because this 


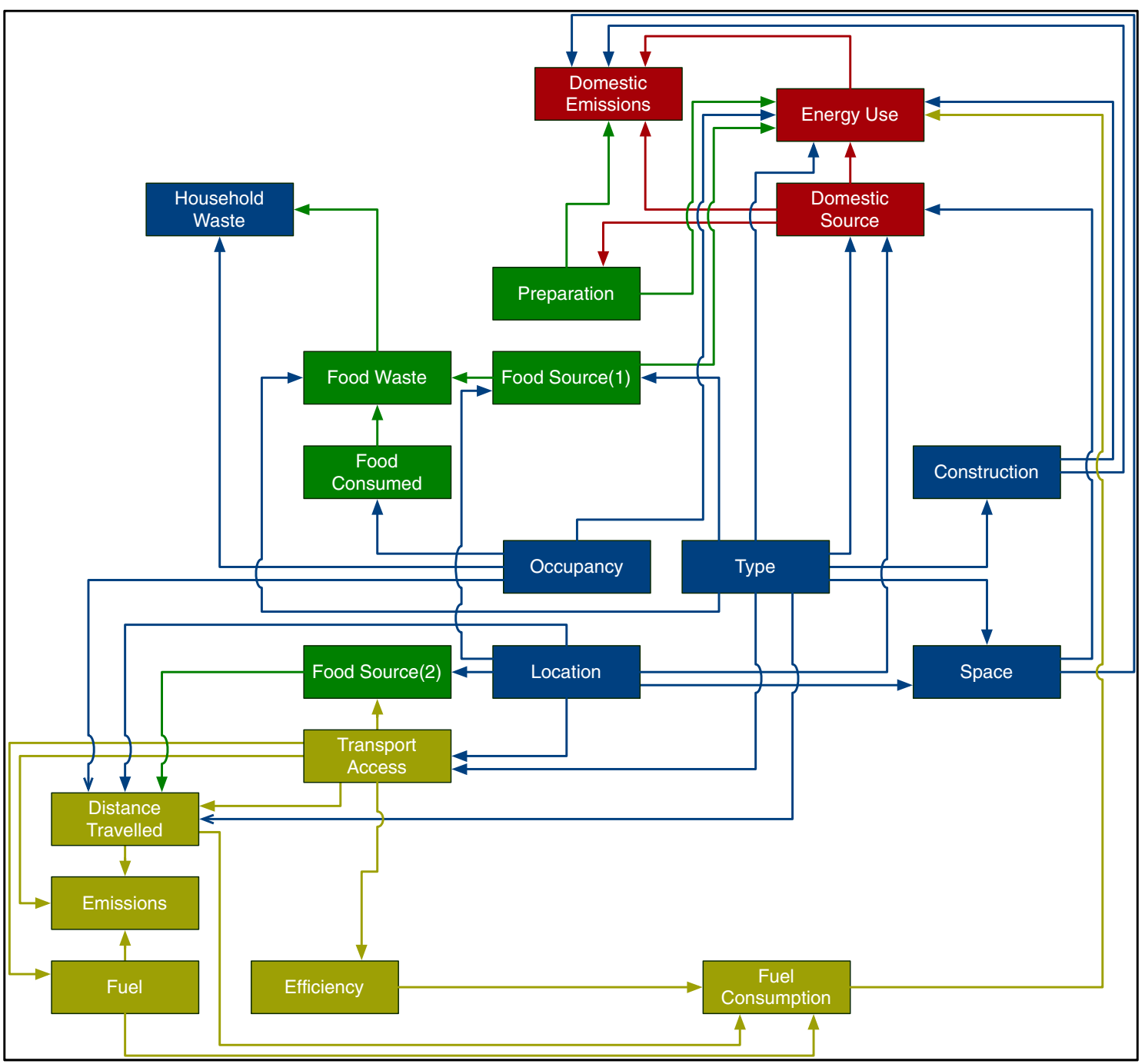

Fig. 1 Integrated household domains: food, energy, living and mobility

happens probabilistically, each time the model is run there might be slight differences.

The innovation adoption process happens annually through the following steps:

Select agents with given probability of adoption from the population.

Remove agents that have already adopted an innovation from the selection.

Remove agents that are not active from the selection.

Remove agents that are not eligible for a particular innovation from the selection (e.g. agents that do not have cars are not eligible for car efficiency innovations). Adopt innovation for agents in the selection and mark them as adopters.

Activate a percentage of previously inactive agents based on the number of adopters.
Model input requirements To run the model, three data sets are required: Scenario, Innovation and Policy/Social adoption.

The Scenario input data concerns the number of households and their different floor areas and occupancies. It also provides details of the food consumed and the waste generated, the number of cars per house, distances travelled, energy consumed, etc. This allows us to see the material and energy 'footprint' of households in the region.

The second input file required is the Innovation Data. The innovations considered are discussed in Sect. 3 .

The third input file required to run the model is that of Policy or societal change data. This can be used to explore the 'adoption process' and explore 'what ifs'. For example, there may be a known barrier to adoption of particular innovations, such as upfront capital requirements, or access to information; or it might be 


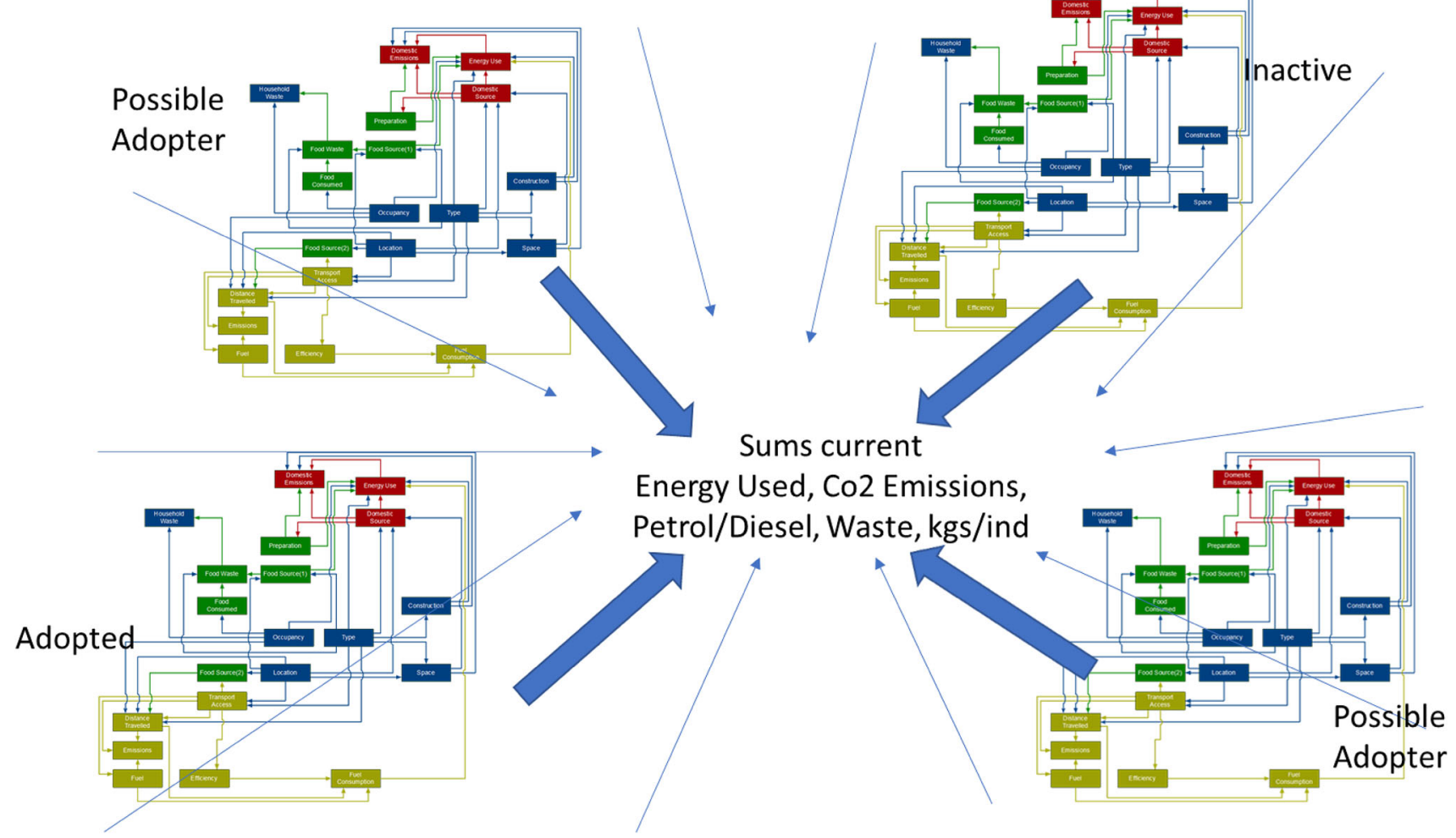

Fig. 2 The model sums over the changing population of agents (here we see four households) with and without the innovation. It calculates the changing levels of energy and material consumed as well as emissions and wastes generated

clear that with improved trust or other societal change, take-up could be improved, leading to more sustainable behaviours. The Policy or social change data allows the user to provide an adoption rate, or a conversion rate, which indicates the speed at which the adoption could be taken up. The model assumes inertia in the system and that there will also be some fraction of households who will not adopt innovations. Further, some households will not be eligible to take up an innovation, because they do not have the essential characteristics, for example, reducing the kilometres travelled by car is impossible for a household with no private vehicles. The adoption rate provided in the data results in a logistic (or sigmoidal) curve of adoption (based on feedback from active households), flattening out to reflect the maximum possible scale of adoption, provided a sufficiently high adoption rate is selected.

Exogenous variables which are not included in the Scenario input file and have no influence on the model processing include: the price of energy (the model assumes that demand is a reflection of affordability), household growth (new households are not created during the model runs, but multiple scenarios can be created and model experiment results can be compared, e.g. a UK 2035 scenario is likely to have a different household constitution) and changing demand (other than from user innovations) are not considered; for example, if demand changes because of energy efficiency improvement in electric vehicles, then a new scenario can be created with this information and model experiment results can be compared.

Non-linearity and feedback are well-known characteristics of complex systems. A non-linearity occurs when a change in one characteristic might lead to more or less than proportional changes in another. For example, adoption of improved insulation can lead towards zero heating demand, due to the increased retention of heat in the household from other energy end uses such as lighting and cooking and also from household occupants. The model has implemented non-linearity for innovations in the living domain. Other non-linearities occur via innovation "Change food source-local" in which fewer kilometres are travelled, also reducing carbon emissions. Similarly, "Change energy source-PV" gives rise to reduced energy supply and to reduced domestic emissions.

Feedback occurs in the adoption process. At initialization, there is assumed to be $80 \%$ inert households and $5 \%$ that stay inert. The entire population is a non-adopter of any innovation at the outset. At each time step, a number of households are selected based on the adoption rate. Any inert households are ignored as are any adopters (after 


\begin{tabular}{|c|c|c|c|c|c|c|c|c|c|c|c|c|c|c|}
\hline \multicolumn{2}{|c|}{ UK Per Pe kWh/yr } & \multicolumn{3}{|c|}{$\mathrm{kgsCo} / \mathrm{yr} \mathrm{kgsCo} 2 / \mathrm{yr} \mathrm{Ltrs} / \mathrm{yr}$} & \multirow{2}{*}{$\frac{\text { Ltrs/yr }}{\text { Petrol }}$} & \multirow{2}{*}{$\begin{array}{l}\text { kgs/yr } \\
\text { Waste }\end{array}$} & \multirow{2}{*}{\multicolumn{2}{|c|}{$\begin{array}{l}\mathrm{kgs} / \mathrm{yr} \quad \mathrm{kgs} / \mathrm{yr} \\
\text { food Wast Food Con }\end{array}$}} & \multicolumn{6}{|c|}{ kgsCo2/yr kgs' } \\
\hline & \multicolumn{4}{|c|}{ Dom Ener, Dom Emis Mob Emis: Diesel } & & & & & Total Emiq & kgs/ind & Reduction & $\%$ Sust & Average & Best \\
\hline Initial & 7964 & 2259 & 1228 & 146 & 158 & 234 & 64 & 565 & 3487 & 32523 & $0 \%$ & & & \\
\hline Coop Livir & $30 \%$ & $43 \%$ & $2 \%$ & $1 \%$ & $4 \%$ & $17 \%$ & $17 \%$ & $0 \%$ & $28 \%$ & $23 \%$ & $23 \%$ & $213 \%$ & & $23 \%$ \\
\hline Improved & $36 \%$ & $29 \%$ & $0 \%$ & $0 \%$ & $0 \%$ & $0 \%$ & $0 \%$ & $0 \%$ & $19 \%$ & $20 \%$ & $20 \%$ & $227 \%$ & $14 \%$ & \\
\hline Reduced & $24 \%$ & $19 \%$ & $0 \%$ & $0 \%$ & $0 \%$ & $0 \%$ & $0 \%$ & $0 \%$ & $12 \%$ & $13 \%$ & $13 \%$ & $254 \%$ & & \\
\hline Reduced & $0 \%$ & $0 \%$ & $0 \%$ & $0 \%$ & $0 \%$ & $34 \%$ & $0 \%$ & $0 \%$ & $0 \%$ & $0 \%$ & $0 \%$ & $306 \%$ & & \\
\hline Reduced $\mathrm{n}$ & $0 \%$ & $0 \%$ & $0 \%$ & $0 \%$ & $0 \%$ & $0 \%$ & $25 \%$ & $25 \%$ & $0 \%$ & $5 \%$ & $5 \%$ & $285 \%$ & & \\
\hline Change sd & $0 \%$ & $0 \%$ & $24 \%$ & $18 \%$ & $34 \%$ & $1 \%$ & $9 \%$ & $0 \%$ & $8 \%$ & $6 \%$ & $6 \%$ & $281 \%$ & $3 \%$ & $6 \%$ \\
\hline Reduce PI & $0 \%$ & $0 \%$ & $0 \%$ & $0 \%$ & $0 \%$ & $0 \%$ & $0 \%$ & $0 \%$ & $0 \%$ & $0 \%$ & $0 \%$ & $306 \%$ & & \\
\hline Reduce Fd & $0 \%$ & $0 \%$ & $0 \%$ & $0 \%$ & $0 \%$ & $0 \%$ & $34 \%$ & $0 \%$ & $0 \%$ & $1 \%$ & $1 \%$ & $304 \%$ & & \\
\hline Reduce $\mathrm{K}$ & $0 \%$ & $0 \%$ & $21 \%$ & $16 \%$ & $29 \%$ & $0 \%$ & $0 \%$ & $0 \%$ & $7 \%$ & $5 \%$ & $5 \%$ & $285 \%$ & & \\
\hline Electric $\mathrm{C}$ A & $-13 \%$ & $-24 \%$ & $51 \%$ & $39 \%$ & $34 \%$ & $0 \%$ & $0 \%$ & $0 \%$ & $2 \%$ & $1 \%$ & $1 \%$ & $302 \%$ & $4 \%$ & \\
\hline Increased & $0 \%$ & $0 \%$ & $21 \%$ & $16 \%$ & $29 \%$ & $0 \%$ & $0 \%$ & $0 \%$ & $7 \%$ & $5 \%$ & $5 \%$ & $285 \%$ & & \\
\hline Change M & $0 \%$ & $0 \%$ & $21 \%$ & $14 \%$ & $35 \%$ & $0 \%$ & $0 \%$ & $0 \%$ & $8 \%$ & $6 \%$ & $6 \%$ & $283 \%$ & & $6 \%$ \\
\hline Reduce Cd & $5 \%$ & $9 \%$ & $0 \%$ & $0 \%$ & $0 \%$ & $0 \%$ & $0 \%$ & $0 \%$ & $6 \%$ & $3 \%$ & $3 \%$ & $296 \%$ & $4 \%$ & \\
\hline PV+ Greel & $0 \%$ & $18 \%$ & $0 \%$ & $0 \%$ & $0 \%$ & $0 \%$ & $0 \%$ & $0 \%$ & $12 \%$ & $6 \%$ & $6 \%$ & $284 \%$ & & $6 \%$ \\
\hline & & & & & & & & & & Total & & & $26 \%$ & $41 \%$ \\
\hline
\end{tabular}

\begin{tabular}{|c|c|c|c|c|c|c|c|c|c|c|c|c|c|c|}
\hline DE Per Pel & ikWh/yr & $\mathrm{kgsCo} / \mathrm{yr} \mathrm{K}$ & $02 / \mathrm{yr}$ & & Ltrs/yr & $\mathrm{kgs} / \mathrm{yr}$ & $\mathrm{kgs} / \mathrm{yr}$ & $\mathrm{kgs} / \mathrm{yr}$ & $\mathrm{kgsCo} 2 / \mathrm{yr}$ & kgs' & & & & \\
\hline & Dom Ener & Dom Emis & Emis: & & Petrol & Waste & Food Was & Food Con & Tot Em & Tot kgs & Reduction & $\%$ Sust & Average & Best \\
\hline Initial & 9029 & 3829 & 1817 & 200 & 333 & 277 & 50 & 535 & 5646 & 53205 & $0 \%$ & & & \\
\hline Coop Livir & $34 \%$ & $47 \%$ & $5 \%$ & $3 \%$ & $7 \%$ & $18 \%$ & $18 \%$ & $0 \%$ & $34 \%$ & $31 \%$ & $31 \%$ & $358 \%$ & & $31 \%$ \\
\hline Improved & $41 \%$ & $37 \%$ & $0 \%$ & $0 \%$ & $0 \%$ & $0 \%$ & $0 \%$ & $0 \%$ & $25 \%$ & $26 \%$ & $26 \%$ & $394 \%$ & $19 \%$ & \\
\hline Reduced & $27 \%$ & $25 \%$ & $0 \%$ & $0 \%$ & $0 \%$ & $0 \%$ & $0 \%$ & $0 \%$ & $17 \%$ & $17 \%$ & $17 \%$ & $451 \%$ & & \\
\hline Reduced & $0 \%$ & $0 \%$ & $0 \%$ & $0 \%$ & $0 \%$ & $37 \%$ & $0 \%$ & $0 \%$ & $0 \%$ & $0 \%$ & $0 \%$ & $564 \%$ & & \\
\hline Reduced & $0 \%$ & $0 \%$ & $0 \%$ & $0 \%$ & $0 \%$ & $0 \%$ & $28 \%$ & $28 \%$ & $0 \%$ & $3 \%$ & $3 \%$ & $543 \%$ & & \\
\hline Change SC & $0 \%$ & $0 \%$ & $30 \%$ & $25 \%$ & $37 \%$ & $1 \%$ & $14 \%$ & $0 \%$ & $10 \%$ & $8 \%$ & $8 \%$ & $509 \%$ & $3 \%$ & $8 \%$ \\
\hline Reduce $\mathrm{Pl}$ & $0 \%$ & $0 \%$ & $0 \%$ & $0 \%$ & $0 \%$ & $0 \%$ & $0 \%$ & $0 \%$ & $0 \%$ & $0 \%$ & $0 \%$ & $565 \%$ & & \\
\hline Reduce Fd & $0 \%$ & $0 \%$ & $0 \%$ & $0 \%$ & $0 \%$ & $0 \%$ & $37 \%$ & $0 \%$ & $0 \%$ & $0 \%$ & $0 \%$ & $563 \%$ & & \\
\hline Reduce $\mathrm{K}_{1}$ & $0 \%$ & $0 \%$ & $30 \%$ & $25 \%$ & $37 \%$ & $0 \%$ & $0 \%$ & $0 \%$ & $10 \%$ & $8 \%$ & $8 \%$ & $511 \%$ & & \\
\hline Electric Ca & $-23 \%$ & $-32 \%$ & $74 \%$ & $62 \%$ & $45 \%$ & $0 \%$ & $0 \%$ & $0 \%$ & $2 \%$ & $-2 \%$ & $-2 \%$ & $575 \%$ & $6 \%$ & \\
\hline Increased & $0 \%$ & $0 \%$ & $30 \%$ & $25 \%$ & $36 \%$ & $0 \%$ & $0 \%$ & $0 \%$ & $10 \%$ & $8 \%$ & $8 \%$ & $512 \%$ & & \\
\hline Change $\mathrm{M}$ & $0 \%$ & $0 \%$ & $32 \%$ & $24 \%$ & $44 \%$ & $0 \%$ & $0 \%$ & $0 \%$ & $10 \%$ & $9 \%$ & $9 \%$ & $504 \%$ & & $9 \%$ \\
\hline Reduce Cd & $0 \%$ & $0 \%$ & $32 \%$ & $24 \%$ & $44 \%$ & $0 \%$ & $0 \%$ & $0 \%$ & $10 \%$ & $9 \%$ & $9 \%$ & $504 \%$ & $9 \%$ & \\
\hline $\mathrm{PV}+\mathrm{Gree}$ & $0 \%$ & $0 \%$ & $30 \%$ & $25 \%$ & $36 \%$ & $0 \%$ & $0 \%$ & $0 \%$ & $10 \%$ & $8 \%$ & $8 \%$ & $512 \%$ & & $8 \%$ \\
\hline & & & & & & & & & & & Total & & $36 \%$ & $57 \%$ \\
\hline
\end{tabular}

\begin{tabular}{|c|c|c|c|c|c|c|c|c|c|c|c|c|c|c|}
\hline \multicolumn{2}{|c|}{ ES Per Per kWh/yr } & \multicolumn{3}{|c|}{$\mathrm{kgsCo} / \mathrm{yr} \mathrm{kgsCo} / \mathrm{yr} \mathrm{Ltrs/yr}$} & \multirow{2}{*}{$\begin{array}{l}\text { Ltrs/yr } \\
\text { Petrol } \\
\end{array}$} & \multirow{2}{*}{$\begin{array}{l}\text { kgs/yr } \\
\text { Waste }\end{array}$} & \multirow{2}{*}{$\begin{array}{l}\mathrm{kgs} / \mathrm{yr} \\
\text { Food Was }\end{array}$} & $\mathrm{kgs} / \mathrm{yr}$ & \multicolumn{6}{|c|}{ kgsCo2/yr kgs' } \\
\hline & Dom Ener; & Dom Emis & Emis: & & & & & Food Con & Tot Ems & Tot kgs & Reduction & $\%$ Sust & Average & Best \\
\hline Initial & 6810 & 1801 & 1596 & 174 & 227 & 225 & 16 & 441 & 3397 & 22362 & $0 \%$ & & & \\
\hline Coop Livin & $27 \%$ & $51 \%$ & $4 \%$ & $1 \%$ & $7 \%$ & $18 \%$ & $18 \%$ & $0 \%$ & $29 \%$ & $19 \%$ & $19 \%$ & $127 \%$ & & $19 \%$ \\
\hline Improved & $33 \%$ & $32 \%$ & $0 \%$ & $0 \%$ & $0 \%$ & $0 \%$ & $0 \%$ & $0 \%$ & $17 \%$ & $10 \%$ & $10 \%$ & $150 \%$ & $9 \%$ & \\
\hline Reduced $\$$ & $22 \%$ & $21 \%$ & $0 \%$ & $0 \%$ & $0 \%$ & $0 \%$ & $0 \%$ & $0 \%$ & $11 \%$ & $7 \%$ & $7 \%$ & $160 \%$ & & \\
\hline Reduced & $0 \%$ & $0 \%$ & $0 \%$ & $0 \%$ & $0 \%$ & $37 \%$ & $0 \%$ & $0 \%$ & $0 \%$ & $0 \%$ & $0 \%$ & $178 \%$ & & \\
\hline Reduced & $0 \%$ & $0 \%$ & $0 \%$ & $0 \%$ & $0 \%$ & $0 \%$ & $28 \%$ & $28 \%$ & $0 \%$ & $6 \%$ & $6 \%$ & $162 \%$ & & \\
\hline Change sd & $0 \%$ & $0 \%$ & $27 \%$ & $20 \%$ & $37 \%$ & $1 \%$ & $34 \%$ & $0 \%$ & $13 \%$ & $14 \%$ & $14 \%$ & $142 \%$ & $5 \%$ & $14 \%$ \\
\hline Reduce PI & $0 \%$ & $0 \%$ & $0 \%$ & $0 \%$ & $0 \%$ & $0 \%$ & $0 \%$ & $0 \%$ & $0 \%$ & $0 \%$ & $0 \%$ & $179 \%$ & & \\
\hline Reduce Fd & $0 \%$ & $0 \%$ & $0 \%$ & $0 \%$ & $0 \%$ & $0 \%$ & $37 \%$ & $0 \%$ & $0 \%$ & $0 \%$ & $0 \%$ & $179 \%$ & & \\
\hline Reduce $\mathrm{KI}$ & $0 \%$ & $0 \%$ & $27 \%$ & $20 \%$ & $37 \%$ & $0 \%$ & $0 \%$ & $0 \%$ & $13 \%$ & $13 \%$ & $13 \%$ & $143 \%$ & & \\
\hline Electric $\mathrm{CA}$ & $-16 \%$ & $-17 \%$ & $67 \%$ & $50 \%$ & $45 \%$ & $0 \%$ & $0 \%$ & $0 \%$ & $22 \%$ & $16 \%$ & $16 \%$ & $135 \%$ & $14 \%$ & \\
\hline Increased & $0 \%$ & $0 \%$ & $27 \%$ & $20 \%$ & $36 \%$ & $0 \%$ & $0 \%$ & $0 \%$ & $13 \%$ & $13 \%$ & $13 \%$ & $143 \%$ & & \\
\hline Change $\mathrm{M}$ & $0 \%$ & $0 \%$ & $28 \%$ & $17 \%$ & $44 \%$ & $0 \%$ & $0 \%$ & $0 \%$ & $13 \%$ & $15 \%$ & $15 \%$ & $139 \%$ & & $15 \%$ \\
\hline Reduce Cl & $9 \%$ & $10 \%$ & $0 \%$ & $0 \%$ & $0 \%$ & $0 \%$ & $0 \%$ & $0 \%$ & $5 \%$ & $3 \%$ & $3 \%$ & $171 \%$ & $5 \%$ & \\
\hline $\mathrm{PV}+$ Greel & $0 \%$ & $24 \%$ & $0 \%$ & $0 \%$ & $0 \%$ & $0 \%$ & $0 \%$ & $0 \%$ & $13 \%$ & $7 \%$ & $7 \%$ & $159 \%$ & & $7 \%$ \\
\hline & & & & & & & & & & Total & & & $34 \%$ & $54 \%$ \\
\hline
\end{tabular}

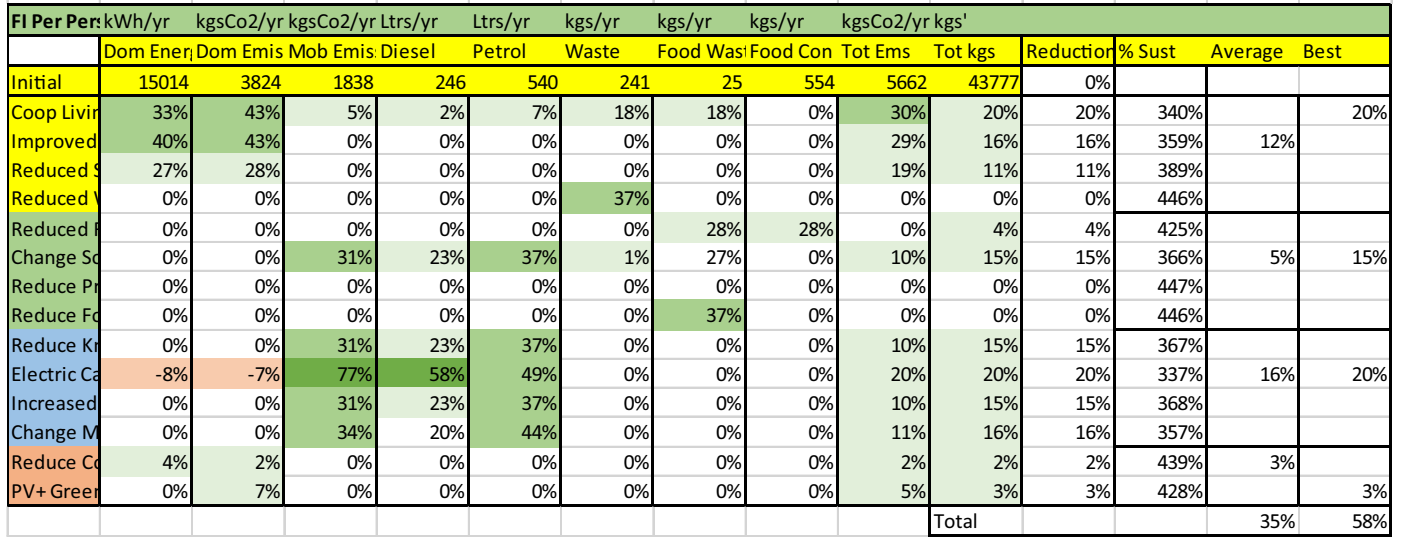


4Fig. 3 The model output in 2050 for the UK, Germany, Spain and Finland with the adoption of innovations in each domain. Shading indicates level of reduction (green) or increase (red)

\begin{tabular}{|c|c|c|c|c|c|}
\hline & & UK & $\mathrm{DE}$ & ES & $\mathrm{FI}$ \\
\hline & $\%$ Reduction in 'kgs' & UK & $\mathrm{DE}$ & ES & $\mathrm{FI}$ \\
\hline & Initial & $0 \%$ & $0 \%$ & $0 \%$ & $0 \%$ \\
\hline & Coop Living & $23 \%$ & $31 \%$ & $19 \%$ & $20 \%$ \\
\hline \multirow[t]{4}{*}{ Living } & Improved Con & $20 \%$ & $26 \%$ & $10 \%$ & $16 \%$ \\
\hline & Reduced Space & $13 \%$ & $17 \%$ & $7 \%$ & $11 \%$ \\
\hline & Reduced Waste & $0 \%$ & $0 \%$ & $0 \%$ & $0 \%$ \\
\hline & Reduced Food & $5 \%$ & $3 \%$ & $6 \%$ & $4 \%$ \\
\hline \multirow[t]{4}{*}{ Food } & Change Source & $6 \%$ & $8 \%$ & $14 \%$ & $15 \%$ \\
\hline & Reduce Preparation & $0 \%$ & $0 \%$ & $0 \%$ & $0 \%$ \\
\hline & Reduce Food Waste & $1 \%$ & $0 \%$ & $0 \%$ & $0 \%$ \\
\hline & Reduce Kms & $5 \%$ & $8 \%$ & $13 \%$ & $15 \%$ \\
\hline \multirow[t]{3}{*}{ Mobility } & Electric Cars & $1 \%$ & $-2 \%$ & $16 \%$ & $20 \%$ \\
\hline & Increased Efficiency & $5 \%$ & $8 \%$ & $13 \%$ & $15 \%$ \\
\hline & Change Mode & $6 \%$ & $9 \%$ & $15 \%$ & $16 \%$ \\
\hline \multirow[t]{2}{*}{ Energy } & Reduce Consumption & $3 \%$ & $9 \%$ & $3 \%$ & $2 \%$ \\
\hline & PV+Green & $6 \%$ & $8 \%$ & $7 \%$ & $3 \%$ \\
\hline
\end{tabular}

Fig. 4 The \% reductions in resource use in the UK, Germany, Spain and Finland resulting from the adoption of the different innovations. Shading indicates the level of reduction (green) or increase (red)

initial adoption). Those remaining become adopters and household behaviours are updated to reflect the innovation. The inert population decays over time at a rate that simulates knowledge of the presence of the innovation and word of mouth advertising, meaning that some households previously inert become active and available to adopt an innovation in the next tick. The process simulates adoption as a logistic (or sigmoidal) curve.

Fig. 5 The decrease in ' $k g$ ' of inputs per individual with different innovations

\section{The model makes some simplifying assumptions}

Large households, with $6+$ residents, are aggregated into a single group, which is why the model assumes that 6 is the maximum occupancy. Such households are a very small part of the population for now.

Household space is measured in $\mathrm{m}^{2}$ and is grouped into 5 bins <50, [50,69], [70,89], [90,109], >110. A minimum space of $20 \mathrm{~m}^{2}$ and a maximum of $300 \mathrm{~m}^{2}$ are assumed. Households are assigned a floor area which is uniformly distributed within these bin ranges.

Household type (binary) is used to distinguish independent housing from cooperative living situations. This is to allow the cooperative/shared living innovation to function.

Household efficiency is assumed to have a triangular distribution with lower and upper values provided in the scenario. As the efficiency of homes improves, both lower and upper bounds can be increased in the scenario data; this would result in innovations having less impact.

Household 'preparation' is a proxy for the amount of cooking performed. This may be improved by the innovation to reduce cooking energy, e.g. by adopting more of a raw food diet.

Households, with 4+ vehicles, are aggregated into a single group, thus are undifferentiated. Five modes of transportation are considered: walking, cycling, car, bus and train. It is assumed that all households have access to public transport and bicycles.

Households which do not possess a car are assumed to use bus and train in equal proportions. Travel as a passenger in a car is neglected, such that fuel consumption and

\section{Reduction in kgs/ind}

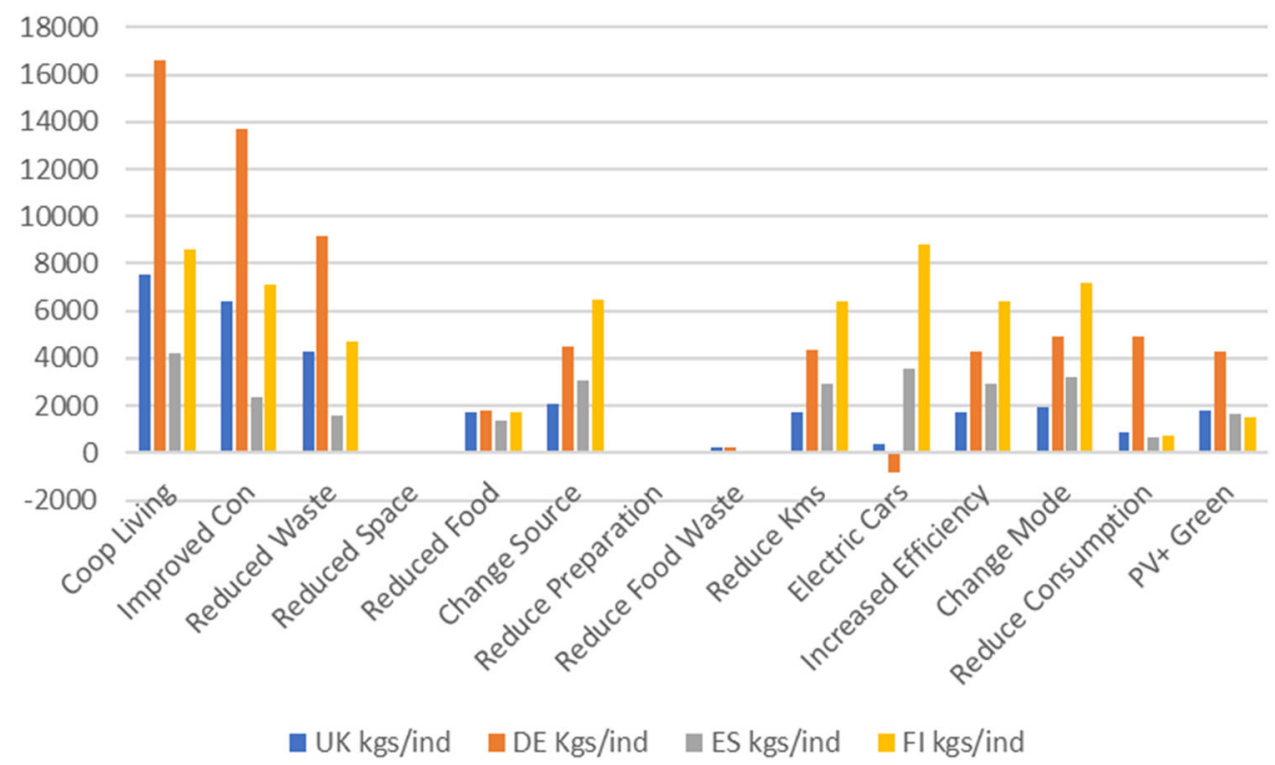


Table 1 The different fractions of households of different sizes for the territory considered

Proportion of households with floor area $<50 \mathrm{~m}^{2}$ A

Proportion of households with floor area range $[50,69] \mathrm{m}^{2}$

Proportion of households with floor area range $[70,89] \mathrm{m}^{2}$

Proportion of households with floor area range $[90,109] \mathrm{m}^{2}$

Proportion of households with floor area $>110 \mathrm{~m}^{2}$

$\mathrm{CO}_{2}$ emissions are attributed solely to household private vehicle schedule.

Rural dwellers travel, on average, further than urban dwellers. It is assumed that rural dwellers travel $30-50 \%$ (uniformly distributed) further than the average household, and urban dwellers travel $5-15 \%$ less than the average household.

Consumption of energy, distance $(\mathrm{km})$ travelled and food consumed and wasted are based on household occupancy and are corrected for non-linearity and feedback effects (see the discussion below) for innovations that are adopted. The model assumes that $66 \%$ of the distance travelled by the hybrid is powered by the electric motor and the remainder uses the petrol engine. It is assumed that all buses and trains run on diesel; electric trains are neglected.

All households are connected to the electricity grid. Gas use for cooking is assumed to be negligible as a large portion of household energy for cooking is provided by electricity (e.g. oven, microwave, toasters, grills).

The amount of energy generated by domestic PV systems depends on the amount of sunlight hitting the panel (varies with time of day, season and weather), the size of the panel and the efficiency of the solar cells inside. Any power not used could be either stored locally in a battery or flow back into the electricity grid, and the model currently "loses" any excess power generated.

An alternative local source for energy generation is an innovation that is accommodated by 'other local source' (e.g. heat pump); the purpose of the innovation might be for heating or other use, and it reduces energy demand appropriately and may contribute to emissions.

Heating is a function of dwelling size (i.e. space) and is not strongly dependent on occupancy. In contrast, the use of hot water and appliances is heavily influenced by occupancy.

Households in the size range of $50-109 \mathrm{~m}^{2}$ are assumed to use the average household heating energy, as input by the scenario data. Households with a floor area less than $50 \mathrm{~m}^{2}$ are assumed to use half this energy for heating and houses with floor area above $110 \mathrm{~m}^{2}$ are assumed to use double the heating energy. Heating energy is multiplied by the household construction factor to account for dwelling energy efficiency.
A grid reduction factor is present to account for a reduction in household emissions from using the electricity grid. Green energy contracts typically work by a "green" company pumping the equivalent amount of energy into the grid as is used by the contracted household. Therefore, while the impact on the grid overall is negligible, the individual household emissions essentially decrease.

A household with a gas meter uses gas for heating and hot water. Households with oil or solid fuel use this for heating only. Households rely on the electricity grid or locally generated power (PV or other) for all other energy needs, and heating if gas, oil and solid fuel are not present.

Over time, households become active and decide to adopt the innovation, and the model shows the growing impact of 'adopters' on the improved and reduced demands for energy and materials made by the population.

At each time step, the model calculates, first, how many households have changed from 'inactive' (not considering innovating) to 'active' (potential adopters), and then how many of these 'actives' actually adopt the innovation in this time step. The model calculates how many households in total have adopted the innovation under study and the resulting overall values of energy and material flows used by the region, as well as the $\mathrm{CO}_{2}$ emissions and the wastes generated. Over time, the innovation spreads through the population, and the model can calculate the overall reductions in energy and materials used by the system, as well as the emissions and wastes generated.

The model sums the energy and material flows for the population under study, which consists of households that are not considering adopting an innovation, ones that are considering it and households that have adopted the innovation. This allows the model to show the changing overall 'sustainability' of the population over time.

\section{Innovations}

Household consumption and waste generation can be altered if a sustainable innovation is adopted.

\section{Living domain innovations}

Innovations in the living domain are categorized by their primary impact on household living profiles as follows:

1. Change type Household switches from being independent to being part of a cooperative housing scheme. This will reduce the heat losses from the household and allow non-heat energy to be retained better, reducing heating energy use per person. Another change is improved access to public transport. Secondary impacts are improved construction, reduced 
food waste, reduced space, reduced household waste, local energy sources, reduced cooking energy and local food sources.

2. Improve construction Household improves energy efficiency. The improved efficiency then creates more retention of all the non-heat energy of a household, reducing still further the amount of heat energy needed. Secondary impacts are reduced energy for heating and reduced domestic emissions

3. Reduce space Household reduces useable floor area. Similarly, the reduced heat losses due to reduced house size also leads to greater heat retention from the nonheat energy used in the house and therefore to reduced energy for heating and reduced domestic emissions.

4. Reduce household waste Household reduces recycled and/or non-recycled waste.

\section{Food domain innovations}

Innovations in the food domain are categorized by their primary impact on household food profiles as follows:

1. Reduce consumption Household reduces the quantity of food consumed/purchased and secondary effects of reduced food and household waste.

2. Change source Household reduces distance travelled for food and/or waste generate from overpurchasing and/or packaging. The secondary effects are reduced kilometres travelled, reduced fuel consumption and reduced emissions.

3. Preparation Household reduces energy used for food preparation. The result is reduced energy for cooking, reduced total energy usage and reduced domestic emissions.

4. Reduce waste Household reduces avoidable food waste and also some household waste.

\section{Mobility domain innovations}

Innovations in the mobility domain are categorized by their primary impact on household mobility profiles as follows:

1. Reduce kilometres travelled Household reduces the kilometres travelled by car, bus or train. This reduces fuel consumption and mobility emissions, as well as domestic emissions for an electric car.

2. Change fuel Household changes car fuel from petrol/ diesel to electricity/hybrid. This will clearly reduce the consumption of petrol and diesel, and the generation of mobility emissions. However, it will increase the use of domestic energy and hence increase domestic emissions.
3. Change mode Household changes the mode of travel (walking, cycling, car, bus, train). This will generally reduce mobility fuel use and emissions, and make public transport more viable.

4. Increased efficiency By switching to highly efficient cars and trucks, as for example, hybrids with motors that stop when the vehicle is halted, and with braking energy recovery, etc. we can diminish fuel consumption by $50 \%$.

\section{Energy domain innovations}

Innovations in the energy domain are categorized by their primary impact on household energy profiles as follows:

1. Reduce consumption Households reduce energy use in one (or several) of the five areas: heating, hot water, lights, appliances or cooking. This clearly reduces domestic emissions as well.

2. Change source Households may install local energy sources (e.g. PV or other) or households may switch to a green energy supply. This will also reduce domestic energy consumption and emissions

\section{Model output}

The model allows us to explore the impacts of different innovations on a given area of study and to show how much a specific innovation may improve the "sustainability' of the region if adopted by many households. In the example shown here, the model tracks the changes within 10,000 households chosen at random. It runs for 35 years from 2015 until 2050. It allows us to see how household decisions to adopt an innovation can improve the overall performance and sustainability of the region under study. In this paper, we can report on the results of applying the model to the UK, Germany, Spain and Finland. We therefore run the model for all the different possible innovations of each domain. The comparison between the different countries reveals their different 'starting situations', as well as how much the actual climate experienced by a region affects the difficulties that will be encountered to becoming 'sustainable'. For each of the four countries, we have the change in resource use and emissions resulting from the implementation of each innovation.

We can explore the different impacts of the same innovations in the different countries. This reflects their different housing patterns, domestic heating choices, climatic constraints, energy and transport infrastructure.

Clearly, the 'living' innovations have the greatest effect on Germany, followed by the UK and Finland. For Spain 
the better climate certainly means that heating is not as great a problem. The 'food' innovations have significant effects for Finland and Germany, particularly through the 'change source' innovation that reduces shopping travel. Finland and Spain respond strongly to the 'mobility' innovations. For the 'mobility innovations' the average reductions in inputs are: Finland $16.5 \%$, Spain $14.25 \%$, Germany $5.75 \%$ and the UK $4.25 \%$. Clearly, for Finland and Spain the 'mobility' innovations offer much larger reductions than for the UK and Germany. The household 'energy innovations' seem to work best for Germany with a $9 \%$ reduction. In this way, the model can indicate where the greatest reductions in 'inputs' may be made from innovations in the different household domains.

As regards $\mathrm{CO}_{2}$ emissions, again the 'living domain' innovations have the greatest effect. Mobility innovations have the next largest effect on $\mathrm{CO}_{2}$ emissions. The only significant impact of the 'food' innovations on $\mathrm{CO}_{2}$, is that for the 'change source' innovation that reduces car travel. For electric vehicles, it is noticeable that Spain and Finland gain most, because of the clean grid electricity that is available.

For the change in $\mathrm{CO}_{2}$ emissions that result from the adoption of the different possible innovations, we find the results as shown in Fig. 6.

Clearly, the most important improvements in consumption and emissions occur for innovations concerning domestic heating and car travel. Finland and Germany reduce $\mathrm{CO}_{2}$ most with the living innovations. Spain, however, seems to get the best $\mathrm{CO}_{2}$ reductions for the innovations concerning mobility. An interesting result seems to arise for the switch to electric vehicles from petrol/diesel. For Spain and Finland there is a significant reduction in $\mathrm{CO}_{2}$ emissions, while for the UK and Germany it is very small. This is because Spain and Finland have relatively clean grid electricity (renewables and nuclear), while the UK and Germany still use a considerable proportion of fossil fuels (Fig. 7).

In Fig. 8, we see the emissions in grams of $\mathrm{CO}_{2}$ per $\mathrm{kWh}$ of electricity for many different countries. This tells us that a switch to electric vehicles will reduce overall $\mathrm{CO}_{2}$ emissions if the grid electricity is below $0.52 \mathrm{~g} \mathrm{CO}_{2}$ per $\mathrm{kWh}$.

This tells us that there will be no benefit at present to the environment from switching to electric vehicles in Cyprus, Czech, Estonia, Germany, Gibraltar, Greece, Hungary, Ireland, Malta, Poland, Romania, Serbia and the UK. In Croatia, Denmark, Italy, the Netherlands and Portugal, it would only give a small improvement.

The important message from this is that unless governments make sure that their electrical generation is much less dependent on fossil fuels than it is at present, then the plans to shift domestic and business consumption towards electricity are quite misplaced. Any switch from gas domestic heating and hot water (80\% of UK homes) to electricity would lead to a significant increase in emissions, and quite contrary to the green commitments that have been undertaken. Similarly, a switch from fossil fuelled
Fig. 6 The \% impact of each innovation for UK, Germany, Spain and Finland

\section{\% Reductions in $\mathrm{CO} 2$ Emissions}

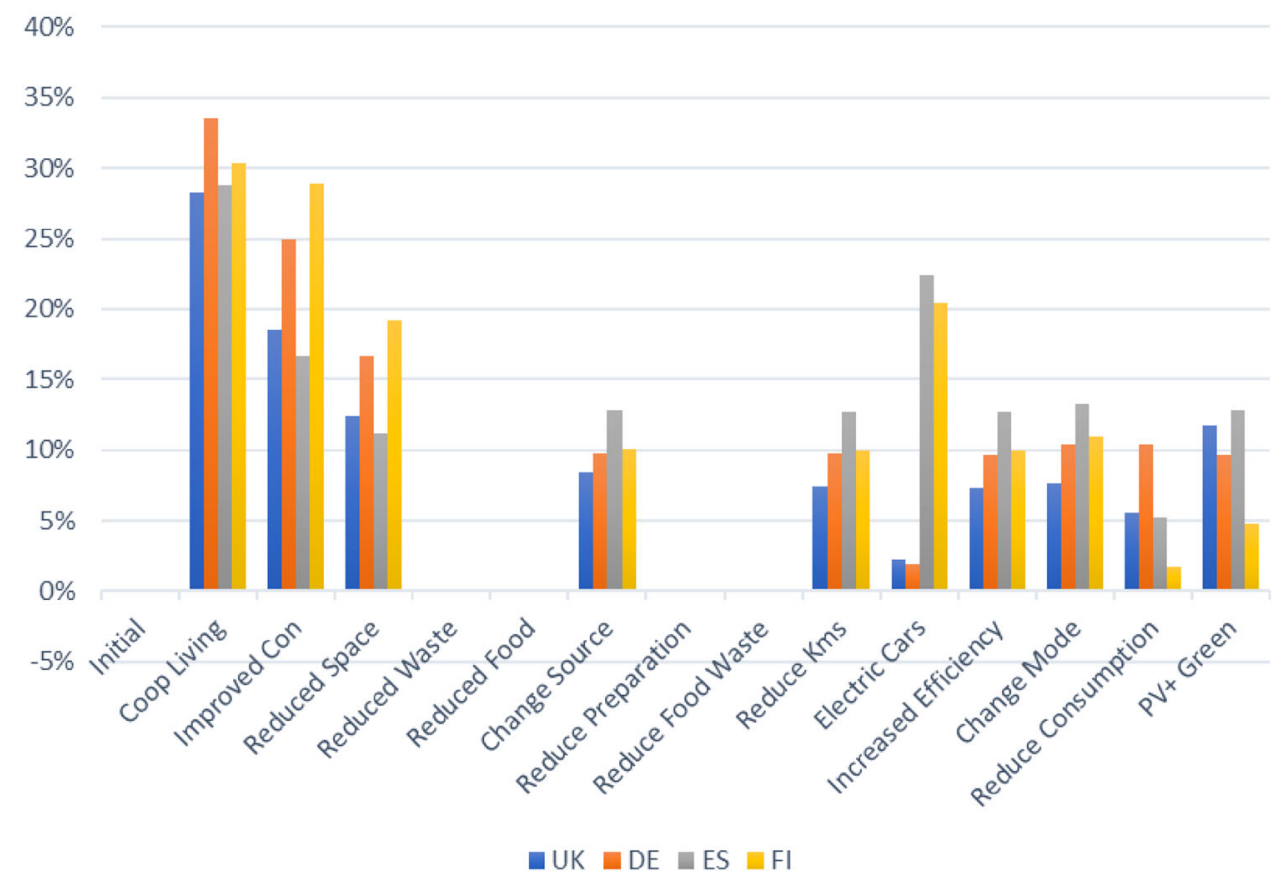




\begin{tabular}{|c|c|c|c|c|}
\hline Emissions & UK & DE & ES & $\mathrm{FI}$ \\
\hline Coop Living & $28 \%$ & $34 \%$ & $29 \%$ & $30 \%$ \\
\hline Improved Con & $19 \%$ & $25 \%$ & $17 \%$ & $29 \%$ \\
\hline Reduced Space & $12 \%$ & $17 \%$ & $11 \%$ & $19 \%$ \\
\hline Reduced Waste & $0 \%$ & $0 \%$ & $0 \%$ & $0 \%$ \\
\hline Reduced Food & $0 \%$ & $0 \%$ & $0 \%$ & $0 \%$ \\
\hline Change Source & $8 \%$ & $10 \%$ & $13 \%$ & $10 \%$ \\
\hline Reduce Preparati & $0 \%$ & $0 \%$ & $0 \%$ & $0 \%$ \\
\hline Reduce Food Wa & $0 \%$ & $0 \%$ & $0 \%$ & $0 \%$ \\
\hline Reduce Kms & $7 \%$ & $10 \%$ & $13 \%$ & $10 \%$ \\
\hline Electric Cars & $2 \%$ & $2 \%$ & $22 \%$ & $20 \%$ \\
\hline Increased Efficier & $7 \%$ & $10 \%$ & $13 \%$ & $10 \%$ \\
\hline Change Mode & $8 \%$ & $10 \%$ & $13 \%$ & $11 \%$ \\
\hline Reduce Consump & $6 \%$ & $10 \%$ & $5 \%$ & $2 \%$ \\
\hline PV+ Green & $12 \%$ & $10 \%$ & $13 \%$ & $5 \%$ \\
\hline
\end{tabular}

\begin{tabular}{|l|r|r|r|r|}
\hline kgs/Ind & UK & DE & ES & FI \\
\hline Best Innovations & 19188 & 22878 & 10287 & 18387 \\
Average Innovations & 24067 & 34051 & 14759 & 28455 \\
\hline Sustainable & 8000 & 8000 & 8000 & 8000 \\
\hline Best Factor & 2.40 & 2.86 & 1.29 & 2.30 \\
Ave Factor & 3.01 & 4.26 & 1.84 & 3.56 \\
\hline
\end{tabular}

Fig. 9 Innovations in all four domains takes Spain quite close to 'sustainability'. The shading indicates how far from sustainable households are: green (close), red (far)

adopted with equal probability (average), or that in each domain only the 'best' most effective innovation is adopted.

The results of running the model for the UK, Germany and Finland show us, in Fig. 8, that even with households adopting the most effective innovations, resource use still remains well over the ' $8000 \mathrm{~kg}$ ' per individual limit for sustainability. Only Spain, at $10,300 \mathrm{~kg}$, gets close to the $8000 \mathrm{~kg}$ limit. To reach 'sustainability', as well as households adopting the innovations studied here, it will be necessary for the UK, Germany and Finland to make very large changes to national and regional infrastructure (clean grid electricity, switching to electric vehicles).

\section{Non-linear effects between household domains}

We can now reflect on the overall improvements that a whole series of household innovations can produce. We can examine the effects of adding together the impacts of innovations in each of the different household domains. We can either suppose that in each domain each innovation is

Innovations made in one domain can affect what occurs in others. In the living domain three innovations have particularly important effects: change type, improve construction and reduce size. These innovations are ultimately concerned with the effect on heat loss.

\section{Grid Electricity and Petrol/Diesel kgCO2/kWh}

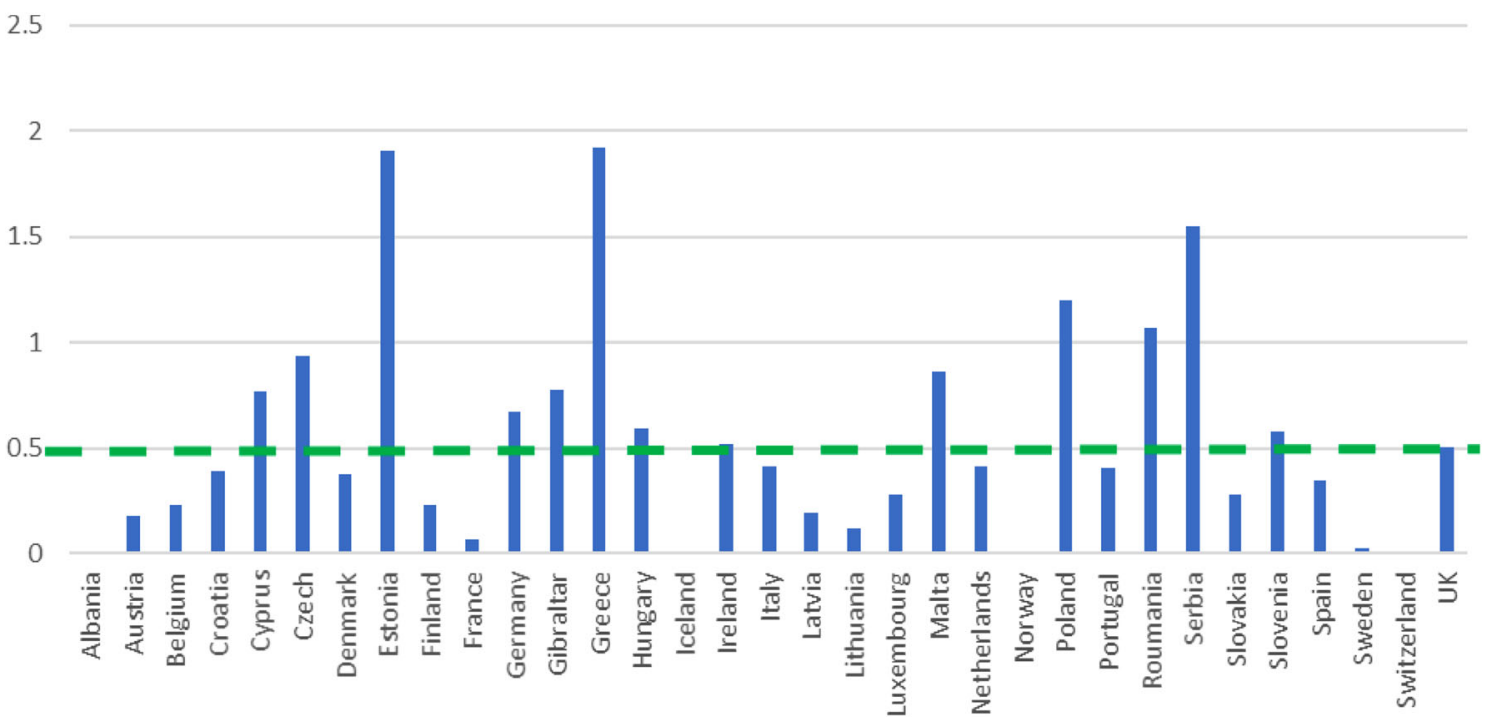

Fig. 8 The $\mathrm{CO}_{2}$ emissions per $\mathrm{kWh}$ of mains electricity across Europe. The line shows where petrol/diesel and electric vehicles cause similar emissions (Brander et al. 2011) 
The total amount of heat transferred is the heat transfer rate integrated over the time interval. The heat transfer rate over area $A$ is the heat flux integrated over the area $A$ and this is proportional to the heat transfer coefficient and the temperature difference between inside and outside. The heat transfer coefficient is proportional to the wall material's thermal conductivity and its thickness.

The total heat transferred depends on the heat flux through wall and roof areas and the time interval. We can therefore calculate the annual heat loss over 1 year from a house. Assuming constant house temperature during the year, the heat lost would be equal to heat gained by running appliances, heating water, lighting, heat produced by human bodies as well as regular heating. Energy that is used in the house for cooking, appliances and lighting also contributes to the heating. For example, energy for TVs, fridges, etc. will directly add to the heating, while most of the energy spent heating water may be lost into the sink. However, this tells us that innovations that reduce energy losses will actually have a 'larger effect than expected' because they will also reduce the heat losses from cooking, lighting, hot water and running appliances. For example, in the UK, a $40 \%$ improvement in insulation can produce a $51 \%$ reduction in heating energy. Also, heating and lighting energy data is given for the household, while the hot water and appliances data is given per person; so we can again correct the impact of particular innovations taking this into account. We also show the effects of changing food supplies to more local sources, thus reducing car travel and carbon emissions. Similarly, an innovation in the energy domain that adopts PV and green electricity will also reduce energy flows and carbon emissions. But equally, decreasing energy used for food preparation may lead to an increase in energy for direct heating. The model looks at each household at each time step, building up the changes for the whole system. It gives an accurate picture of the reductions in energy and material flows as well as in carbon emissions and the degree to which sustainability has been improved.

\section{Policy implications}

The results of the model show us how each of these innovations would grow and spread over time. But it is not a prediction of the overall evolution of the countries studied towards a sustainable lifestyle. It is really simply a test of the relative effectiveness of different possible innovations-if they spread according to the 'adoption rates' supposed in each simulation. In reality, these 'adoption rates' will depend on many factors. One will be the 'gain' to the household of the adoption of an innovation. The more positive this is (like improving insulation in a cold country), then the more likely this will happen. In Nordic countries, the winter climate means that they have already adopted high levels of insulation, and these are enshrined in the building regulations. The gains arising from further increases in insulation are therefore not large and the focus may need to be on travel for work, shopping and pleasure. Also, as households adopt high levels of insulation and electric vehicles with clean electricity, the focus will move to the inputs required for household food requirements. The model, however, takes into account the non-linear effects of innovations across different domains, as for example, better insulation in the 'living' domain can mean that energy used in cooking, washing, etc. can be better retained and reduce the need for heating energy. Similarly, reduced travel for food shopping and the adoption of PV energy by a household will both decrease emissions.

A sustainable lifestyle may well require the adoption of a 'low meat' cuisine. In the warm countries of the Mediterranean, there is less incentive to insulate homes further. However, people do seem to travel longer distances than in the UK, for example, and so some of their climatic advantages result in higher consumptions of mobility. In these countries, without some public policy stimulus we probably will not see much increase in household heat insulation because there is not sufficient advantage. The model can of course calculate the overall cost/benefit of greater insulation and provide information to help decide whether this is a worthwhile choice for policy action.

All this points to the fact that without public policies of incentives, price increases for energy and natural resources or legal obligations, the pace of change towards sustainable lifestyles will not be rapid. More importantly, the model allows us to show that the UK, Germany and Finland cannot fulfil their international obligations in reducing $\mathrm{CO}_{2}$ emissions or attain sustainability (8000 kg inputs/person) without improving the national infrastructure. Our model underlines the fact that because it takes $2.2 \mathrm{kWh}$ to generate $1 \mathrm{kWh}$ for the electricity grid, simply changing over to electric vehicles is not a solution. We must also switch the generation of electricity from gas or coal to renewables and nuclear sources. Our model demonstrates that without the active adoption and continuation of environmental policies by the different levels of government, these countries cannot attain sustainable lifestyles-approach $8000 \mathrm{~kg} /$ person of input requirements.

The model presented here focuses on specific possible actions and changes of behaviour that households could take up by using specific entrepreneurs to make the necessary changes. The model has been designed to allow potential innovations to be 'tested' for their effects. It is, therefore, neither a 'forecasting' model for the system nor a 'backcasting' one. It provides information that can 
influence the choice of which innovations are most effective in increasing sustainability. There is an element of 'backcasting' when considering to what extent various innovations may take the household footprint closer to the $8000 \mathrm{~kg}$ /individual goal that has been put forward by the Wuppertal Institute as being 'sustainable'. It certainly provides a reasonable measure of the 'distance' from sustainability. However, as each country studied will have different ecological, geographical, climatic, social, economic and political factors in play, it would be necessary to examine each case separately for a more accurate measure. However, all the countries studied are sufficiently far from a sustainable situation, even in Spain, that it provides us with an adequate measure at present.

It recognizes the fact that households are already complex systems of at least four different domains of human activity. These are living, food, mobility and energy. Innovations made in any one of them may affect only one or any or all of the others. This is captured in the model by the concept of primary and secondary impacts of innovations. The outcomes presented only show the effects of each innovation separately to make a clear comparison. Different households would adopt different innovations at different times: some adopting a single innovation and others adopting several.

The impacts shown here tell us that the innovations considered would take us quite a lot nearer to sustainability than is presently the case. They therefore show us practical measures that can take us towards a sustainable future, and which innovations, if adopted, would provide the most progress. This allows us to guide policy initiatives in the most advantageous direction for each of the cases studied. The model here is only the first step in creating a useful tool with which to explore the impacts of further innovations, or of changing technology in different countries. It can indicate which innovations are most important under different climatic and socioeconomic situations. It will also help us to map a course towards more sustainable lifestyles and clarify what steps, innovations, policies and actions will be necessary. It will provide a guide as to where public policy support will enjoy the greatest return for incentives affecting specific innovations. We believe therefore that this paper and the model it describes would help us advance both the science of sustainability and its application in the real world.

Acknowledgements This research is part the large-scale project 'Sustainable Lifestyles 2.0: End User Integration, Innovation and Entrepreneurship (EU-InnovatE)'. The project has received funding from the European Union's Seventh Framework Programme for research, technological development and demonstration under grant agreement no. 613194. We would like to thank Julia Binder at the TUM, Angelina Korsunova for Finnish data, and Spanish data from Xavier Fernández i Marín and also J.M. Gonzalez de Durana. The authors would also like to thank the reviewers of this paper for their very helpful suggestions and comments. The data for the models runs was found on Eurostat and on the National databases of UK, Germany, Spain and Finland.

Open Access This article is distributed under the terms of the Creative Commons Attribution 4.0 International License (http://creative commons.org/licenses/by/4.0/), which permits unrestricted use, distribution, and reproduction in any medium, provided you give appropriate credit to the original author(s) and the source, provide a link to the Creative Commons license, and indicate if changes were made.

\section{References}

Advancing sustainability science: report on the International Conference on Sustainability Science (ICSS) 2009, Joanne Kauffman

Allen PM (2013) Evolution: complexity, uncertainty and innovation. J Evol Econ 22(7):702-725 (Springer, Berlin, Heidelberg)

Bonabeau E (2002) Agent-based modeling: methods and techniques for simulating human systems. Proc Natl Acad Sci USA 99:7280-7287. https://doi.org/10.1073/pnas.082080899 (PMC 128598 Freely accessible. PMID 12011407)

Brander M, Sood A, Wylie C, Haughton A, Lovell J (2011) Electricity-specific emission factors for grid electricity. 41. https://ecometrica.com/assets/Electricityspecific-emission-fac tors-for-gridelectricity.pdf. Accessed 20 June 2018

Dodman D (2009) Blaming cities for climate change? An analysis of urban greenhouse gas emissions inventories. Environ Urban 21(1):185-201

Forrester J (1961) Industrial dynamics. Pegasus Communications, Waltham

Garcia-Mera R, Dumitru A, Alonso-Betanzos A, Sanchez-Morono N, Fontenla-Romero O, Craig T, Polhill JG (2017) Testing scenarios to achieve workplace sustainability goals using backcasting and agent-based modeling. Environ Behav 49(9):1007-1037

Gilbert N (2007) Agent-based models (Quantitative Applications in the Social Sciences). Sage Publications

Gomi K, Shimada K, Matsuoka Y, Naito M (2007) Scenario study for a regional low-carbon society. Sustain Sci 2:121-131

Holland JH (1996) Hidden order: how adaptation builds complexity (1 ed). Addison-Wesley, Reading, Mass. (ISBN 978-0-20144230-4.2011)

Ivanova D, Stadler K, Steen-Olsen K, Wood R, Vita G, Tukker A, Hertwich EG (2016) Environmental impact assessment of household consumption. J Ind Ecol 20(3):526-536

Palmer J, Cooper I (2012) United Kingdom housing energy fact file, DECC

Lettenmeier M, Liedtke C, Rohn H (2014) Eight tons of material footprint-suggestion for a resource cap for household consumption in Finland. Resources 3:488-515. https://doi.org/10. 3390/resources3030488 (ISSN 2079-9276, http://www.mdpi. com/journal/resources)

Lettenmeier M, Rohn H, Liedtke C, Schmidt-Bleek F (2009) Resource productivity in 7 steps. How to develop eco-innovative products and services and improve their material footprint; wuppertal spezial 41. Wuppertal Institute for Climate, Environment and Energy: Wuppertal, Germany

Meadows DH, Randers J, Meadows DL (2004) Limits to growth-the 30 year update

Miller JH, Page SE (2007) Complex adaptive systems: an introduction to computational models of social life. Princeton University Press, Princeton (ISBN 978-0-691-12702-6) 
Paris agreement on Climate Change (2016) European Agreement on 80\% reduction in CO2 1990 emission by 2050. In the UK, Alex Bowen and James Rydge, 2011, "Climate change policy in the United Kingdom", Policy paper by Centre for Climate Change Economics and Policy and the Grantham Research Institute on Climate Change and the Environment, LSE

Prigogine I (1997) The end of certainty. The Free Press, New York Rijnhout L, Lorek S (2011) EU Sustainable lifestyles roadmap and Action Plan 2050. Pathways for enabling: Leida Rijnhout and Sylvia Lorek (ANPED) With inputs from the project consortium, project advisors and the European Social Platform on Sustainable Lifestyles, Brussels

Ritthoff M, Rohn H, Liedtke C (2002) Calculating MIPS-Resource Productivity of Products and Services, 1st ed.; Wuppertal Spezial 27e, Wuppertal Institute for Climate, Environment and Energy: Wuppertal, Germany

Robinson JB (1990) Futures under glass: a recipe for people who hate to predict. Futures 22(8):820-842

Sterman JD (2000) Business dynamics: systems thinking and modeling for a complex world. McGraw, New York

The sage handbook of complexity and management (2011) Allen P, Maguire S, McKelvey B (eds), (Print ISBN: 9781847875693 Online ISBN: 9781446201084)

Tukker A (2015) Product services for a resource-efficient and circular economy-a review. J Clean Prod 97(1):76-91

Van der Veen RAC, Kisjes KH, Nikolic I (2017) Exploring policy impacts for servicising in product-based markets: a generic agent-based model. J Clean Prod 145(2017):1-13 